\title{
Exploring the Adoption of E-Government Tools with WISE Work Index
}

\author{
Esther Ruiz Ben, Margit Scholl*, Peter Ehrlich
}

\section{Zusammenfassung}

In diesem Beitrag erläutern wir die Entwicklung eines Analysetools (Wildau Information System Evaluation [WISE] Work Index) zur Erforschung der Einführung innovativer E-Government-Anwendungen und zeigen erste Evaluationsergebnisse bezogen auf die Anwendung „eAkte“. Wir argumentieren, dass die mit dem Einsatz von E-Government-Anwendungen und -Tools verbundenen Innovationsprozesse für die Arbeitsteilung und die organisatorischen Aspekte der Arbeit kontinuierlich Unsicherheiten erzeugen können. In einigen Fällen könnte die unreflektierte Einführung von E-GovernmentTools für die Arbeitseffektivität und -effizienz sogar negativ sein. Eine kontinuierliche Bewertung mit dem WISE Work Index und ein partizipatives Redesign von E-Government-Tools könnten helfen, negative E-Government-Gewohnheiten zu vermeiden. Unser Forschungsziel ist zudem, unseren WISE Work Index selbst durch die Analyse seiner Anwendung auf EGovernment-Tools unter Beschäftigten des öffentlichen Sektors zu verbessern. Wir untersuchen mit unserem Index, wie Beschäftigte des öffentlichen Dienstes neue E-GovernmentTools in ihrer täglichen Arbeit nutzen, wie sie den Nutzen der Tools wahrnehmen und wie sie ihre früheren Arbeitsabläufe an die neue IT-Umgebung anpassen. Die Implementation unseres Indexes macht es möglich, die Auswirkung der Verwendung von E-Government-Online-Diensten sowie deren Inhalte zu verfolgen und konkrete Vorschläge für die Führungskräfte der öffentlichen Verwaltung anzubieten, um den öffentlichen Wert ihrer Informations- und Kommunikationstechnologien (IKT) einschließlich Arbeitnehmersichten zu verbessern und die öffentliche Informationsdienste im aktiven Co-Design zu entwerfen.

\section{Abstract}

In this paper, we explain the development of an analysis tool (Wildau Information System Evaluation [WISE] Work Index) for exploring the adoption of innovative E-Government applications and for presenting preliminary results regarding the application "eAkte". We argue that the innovation processes characterized by the use of E-Government applications and tools continually transform the division of labour and the organizational aspects of work in uncertain ways. In some cases, adopting E-Government tools might exert a negative influence on work effectiveness and efficiency. A continuous evaluation and a participative redesigning of E-Government applications might help to avoid negative adopting habits in E-Government. Our research goal is to improve our WISE Work Index which aims at analysing the adoption of E-Government tools among public sector employees. Through our index, we explore how public employees use new E-Government tools in their day-to-day work, how they perceive the usefulness of the tools, and how they adapt their former working routines to the new IT environment. Implementing our index makes it possible to monitor the impact of using E-Government online services as well as their content and to offer concrete suggestions to public managers about ways to enhance the public value of their information and communicaation technologies (ICT) including employees' views on actively co-designing the public informational services.

\section{Introduction}

The term E-Government has been shaped by the claim that information and communication technologies (ICT) would enable innovative direct-democratic practices. However, rapid changes in technology itself and the difficulties in predicting the impact of innovating with E-Government tools make it hard to foresee the effectiveness of E-Government in fulfilling this promise. The main challenge involved in innovating with E-Government is not just the functionality of information technologies but also their participative adaptation or institutionalization within the particular political or bureaucratic situations. Such a participative institutionalization could lead to a better communication and cooperation across public organizations, but also to the specialization of public organizations and their eventual fragmentation. To include the diverse participants' perspectives and needs more effectively in the introduction of E-Government instruments in public organizations, it is necessary to focus the innovation analysis on adopting 
these instruments for concrete practices and context, and specific analysis tools are needed for this aim.

On the basis of empirical evidence extracted from several studies in the area of E-Government implementation, we have taken the developed evaluation tool TEDS*MOODLE (Scholl et al. 2014) a great deal further, presenting the analytical framework WISE (Wildau Information Systems Evaluation) Work Index for analysing the impact of E-Government applications in public-sector work environments. TEDS*MOODLE is a finely structured, analytical instrument with 33 criteria for evaluating information artifacts (IA), specifically emphasising the actors and usage, thus providing user-oriented quality. Several different IA were evaluated regarding the user experience of various target groups (Scholl 2015). However, for evaluating E-Government applications within a working process, TEDS*MOODLE had to be changed by compressing the criteria for the pure system review and complementing the factors for assessing the work situation. For that, in theoretical terms, we moved away from technology-acceptance models toward the technology focused on and developed an evaluation model to assess the impact of these tools on the work habits and organizational dynamics. The application of our evaluation model responds to previous findings of the need for more participative designs for developing E-Government tools.

More concretely, this is based upon the main lessons learned from our previous empirical analysis (Meier et al. 2013, Ruiz Ben \& Schuppan 2014):

- Employees should participate in the initial phase of the innovation, not just as information "receivers" but with an active role in the innovation design. This means establishing a dialogue in order to communicate and make visible the needs of the organization and the users of the new electronic tools.

- During the implementation phase, the technology design should take into account the tool's specific social learning in employee work practices. This includes a flexible connection with existing tools and different departments. The design should thus be flexible enough to enable tool changes prompted by new work practices emerging through the use of the tool.

- Training should be developed on the basis of the employees' working needs as a means to help the organization adapt. The scope of the training should be considered from a long-term perspective and not just as an isolated measure. Social innovations, such as ongoing mutual help between employees, could improve support for the tool and motivate staff to use it.

In this paper, we focus on developing our index as an evaluation tool and presenting the preliminary results of its empirical application in a large public-sector organization pertaining to the "eAkte" (electronic administrative file documents). We explain our theoretical basis in Chapter Two and then go on to refer to the methodology used for developing of our evaluation tool and for its empirical testing in Chapter Three. In the last parts, we present the results of our testing in Chapter Four, conclude with a short summary and critical discussion of our results in Chapter Five, and offer an outlook in Chapter Six.

\section{Theoretical Basis}

The scope of research conducted on information systems and tools has expanded during the last decade to include a wide range of disciplines. In order to gain insights into the quality of such information artifacts (IA), these should be analysed using a clearly structured and well-organized approach that specifically allows for the different usage scenarios and the variety of users involved (Scholl et al. 2011, Taylor 1982). Evaluation tools have been developed, like the integrated application TEDS*MOODLE (Scholl et al. 2014), which can be universally applied to different IA scenarios on different devices (Scholl 2015) for obtaining detailed user-experience (UX) data and which might also be an innovative solution for E-Government platforms and tools. Moreover, in general, technology acceptance models (TAM) (Davis 1985, Davis et al. 1989, King \& He 2006, Venkatesh \& Davis 2000, Venkatesh et al. 2003, Venkatesh \& Bala 2008) are widely used tools for analysing innovations in implementing electronic government services. However, these models are unduly focused on the technological aspects emphasizing individual usage pattern issues, despite that technology acceptance is not just an individual matter. Focusing on E-Government organizations, we argue that technology acceptance is an important aspect of transforming public-sector organizations associated with a larger process of technological, organizational, social, and work innovation. Analysing the transformation of public-sector organizations needs to consider the whole innovation process, including the social, organizational, and work-related factors that influence resistance to or support for the new technologies. Innovation and acceptance, or resistance to change, involve the social processes of learning, sense-making, and flexibly adapting the practices taking place in the interactions between the actors involved at different moments of the work-transformation process, as numerous social and organizational research analyses have shown (Brown \& Duguid 1991, Weick 1979, Argyris \& Schön 1978, Cicourel 1990, Hippel 2001). Moreover, the division and categorization of tasks, as well as their fragmentation and consolidation, may simultaneously occur when introducing electronic tools into the work processes (Huws 2003, Ruiz Ben 2013). This means that new activities, or the recombination and concentration of diversified tasks into a single activity, occur in the innovation process when introducing the electronic tools. Thus, employees themselves must confront the change in requirements for using the electronic tools in their day-today tasks, while interacting with their colleagues and informally creating organizational strategies for supporting or resisting the innovation process. In summary, the analysis of E-Government and E-Governance must go beyond the individual and technological perspectives of employees in public-sector organizations. More extensive research should consider how the 
multiple contextual, social, functional, and technological factors in the course of a whole innovation process influence the resistance to and support for the electronic records systems in public-sector organizations and specific analysis models are needed for that. Our analysis model is theoretically based on the ideas of Ebbers and van Dijk (2007) (Meier et al. 2013), who consider the total innovation process of introducing electronic tools into public-sector environments. We have, in previous publications, explained our theoretical adaptation of this model for analysing innovation in the public sector (Meier et al. 2013). Our adaptation of the Ebbers and Van Dick (2007) model distinguishes two innovation phases in several dimensions: first, initiation (gestation, perception of urgency, plan) and second, implementation (management involvement, adaptation of the innovation, adaptation of the organizational structure, deploying information systems). Concretely, during these two innovation phases, we concentrate on the following topics: the initial phase focuses on the gestation of the innovation, the perception of an urgency of introducing a new electronic tool, and the plan for introducing it. The implementation phase focuses on involving the management, adapting the technology, adapting the organizational structure, as well as deploying the information systems (Meier et al. 2013).

We have introduced these topics in our WISE Work Index to analyse the impact of innovative E-Government tools in public-sector work environments on our development of TEDS*MOODLE (Scholl et al. 2014). Using the WISE index, we want to overcome not only the linearity of previous theories but also the one-sided perspective of the individually, organizationally, and technologically determined approaches. Our test scenario concretely focuses on determining whether the questions/pointers developed to clarify the evaluation criteria for the users are correctly understood by the respondents. At the same time, the test results offer a short-term, limited view of the respondents' user experiences of applying a particular document management system (DMS) - in this case, eAkte. We apply the WISE Work Index empirically to answer questions about the introduction of electronic records systems (ERS) in a public-sector organization in Germany. In the next section, we describe our tool WISE and the methodology used for testing it.

\section{Methodology and Model Tool Development}

The original evaluation tool for IA, the TEDS*MOODLE, was developed according to the methodology of the TEDS framework (Scholl et al. 2011), which itself was a significant extension of the Taylor value-added model of information systems (Taylor 1982), which strongly focused on the needs of the human actors using the information systems. The TEDS framework and the tool TEDS*MOODLE distinguishes the following six main evaluation categories - these are then divided up, using what is known as a scorecard, into further sub-criteria to be applied in the actual assessment of the information artifact: Ease of Use, Noise Reduction, Quality, Adaptability, Performance, and Affection (Scholl et al. 2014). The evaluation tool available with TEDS*MOODLE delivers very detailed results concerning the IA investigated. However, this generated comprehensive framework is an evaluation tool for IA-like information systems and does not provide direct insight into the process of the working itself. Therefore, we changed and reduced the criteria, as well as added new criteria, concerning an evaluation

Tab. 1: Test participants' age of the working processes with IA. We introduced other categories about the employees' involvement in the innovation process as well as about their attitudes toward working with the new system and their acceptance of the new electronic tool. We have developed WISE through the combination of these categories theoretically grounded in our extension of the Ebbers and Van Dick analytical model. For checking the validity of our evaluation tool, we have developed a test in one public-sector agency in October 2014. The sample includes 19 people who were asked to participate in the test by the managers of the agency. Two people from the sample did not take part in the test. The test took place in two rooms of the agency where computers were provided. The participants received an Internet address that gave them access to WISE. The participants were informed of the objectives of the test and its importance for the further development of the eAkte. We also showed the participants the structure of the questionnaire and offered them our support whenever they had any technical or comprehension problems. The test took about 45 minutes, and at the end, we also had the opportunity to discuss any redundancies or missing aspects that the test participants thought were particularly relevant to include. Regarding the demographics of the sample, the age groups "31-45 years" and "over 55 years" were particularly strongly represented (see Tab. 1). The distribution of gender

\begin{tabular}{|c|c|c|c|}
\hline & & Frequency & Per cent \\
\hline \multirow[t]{6}{*}{ Missing } & 0 & 2 & 10.5 \\
\hline & under 30 years & 1 & 5.3 \\
\hline & between 31 and 45 years & 7 & 36.8 \\
\hline & between 46 and 55 years & 3 & 15.8 \\
\hline & over 55 years & 6 & 31.6 \\
\hline & Sum & 17 & 89.5 \\
\hline Total & & 19 & 100.0 \\
\hline
\end{tabular}


was approximately equal (see Tab. 2). Slightly more than half of the participants have been working in the organization for more than 20 years (Tab. 3), and a majority of over $70 \%$ have had several years of experience with the eAkte (Tab. 4).

4. Results

\subsection{Attitudes toward the impact of working with the eAkte}

\subsubsection{Usage behaviour}

Frequency of use (time utility): The majority of the participants (31.8\%) are using eAkte throughout their working day (7-8 hours). There are no participants using the tool for less than three hours per day (see Fig. 1).

Printing behaviour (print behavior): Although most of the participants (28.6\%) print documents very rarely, a certain proportion of participants (19\%) still do it.

\subsubsection{Perceived advantages of working with the eAkte}

Access to the documents (files access): As shown in Fig. 2, the majority of the participants (47.6\%) agree and $28.6 \%$ of the participants strongly agree with the statement that they have better access to documents when using the eAkte than when not using it. Only $4.8 \%$ of the participants do not agree that the tool led to an improvement in document accessibility.

Reduction in face-to-face communication (communication shortcuts): Although most of the participants (28.6\%) show a neutral attitude toward the statement about the reduction in face-to-face communication caused by using the eAkte $23.8 \%$ agree, and a further $23.8 \%$ of the participants strongly agree with the statement.

Reduction in team communication (communication shortcuts in team): In contrast to the previous item, although most of the participants (33.3\%) express a neutral opinion about the statement regarding the reduction in team communica-

Tab. 2: Test participants' gender

\section{Gender}

\begin{tabular}{|c|c|c|c|}
\hline & & Frequency & Per cent \\
\hline Missing & 0 & 2 & 10.5 \\
\hline & momen & 9 & 47.4 \\
\hline & Sum & 8 & 42.1 \\
\hline Total & & 17 & 89.5 \\
\hline
\end{tabular}

Tab. 3: Test participants' length of experience in the agency

\section{Experience in the Organisation}

\begin{tabular}{|c|c|c|c|}
\hline & & Frequency & Per cent \\
\hline \multirow[t]{4}{*}{ Missing } & 0 & 2 & 10.5 \\
\hline & 10 to 20 years & 6 & 31.6 \\
\hline & over 20 years & 11 & 57.9 \\
\hline & Sum & 17 & 89.5 \\
\hline \multicolumn{2}{|l|}{ Total } & 19 & 100.0 \\
\hline
\end{tabular}

Tab. 4: Test participants' length of experience with the E-Akte

\section{Experience with the Tool}

\begin{tabular}{|c|c|c|c|}
\hline & & Frequency & Per cent \\
\hline Missing & 0 & 2 & 10.5 \\
\hline & under 2 years & 3 & 15.8 \\
\hline & 2 to 5 years & 14 & 73.7 \\
\hline & Sum & 17 & 89.5 \\
\hline Total & & 19 & 100.0 \\
\hline
\end{tabular}

tion as a result of working with the eAkte, $28.6 \%$ of the participants do not agree and $4.8 \%$ strongly disagree, $14.3 \%$ agree and $9.5 \%$ strongly agree with this statement. This means that the participants see the eAkte as affecting the reduction of face-to-face communication, but not team communication, which might indicate that technology-based communication has replaced face-to-face communication for team working purposes.

Improvement of work quality (work quality): When asked about the improvement of work quality through using the eAkte, most of the participants (33.3\%) express a neutral opinion. 
However, $28.6 \%$ of the participants do not agree that the eAkte has improved the quality of their work, and $19 \%$ of the participants strongly disagree with the statement.

Acceleration of work output (workflow speed): Work output has been accelerated by using the eAkte, in the opinion of the majority of the participants (38.1\%). Nevertheless, 19\% of the participants express a neutral opinion about the statement. $14.3 \%$ do not agree, and $9.5 \%$ strongly disagree with the statement.

Improvement of work output (process amount): Although most of the participants $(28.6 \%)$ agree with the statement that they achieve an improvement in their work output using the eAkte, $19 \%$ of the participants show a neutral opinion about the statement. Moreover, $19 \%$ of the participants do not agree, and a further $19 \%$ strongly disagree with the statement.

In summary, while running the implementation phase of the innovation with the eAkte, the employees perceive some benefits in their work using the new tool regarding access to documents or improving their work output. However, the employees do not strongly agree with the benefits of the eAkte in their work. Moreover, they show that their communication habits have changed by the eAkte usage during the innovation journey.

\subsubsection{Technology Acceptance Model (TAM)}

Ease of use (easy to use): The majority of the participants (47.6\%) agree that the eAkte is easy to use and $9.5 \%$ totally agree with the statement (Fig. 3). However, $23.8 \%$ have a neutral opinion and $9.5 \%$ do not agree that the usage of the eAkte is easy.

Clarity of use (handling): Although a majority of the participants (38.1\%) agree that the use of the eAkte is clear and understandable, $33.3 \%$ of the participants have a neutral opinion, and $14.3 \%$ do not agree with the statement.
Productivity: A majority of the participants (42.9\%) agree that they can be more productive in their work using the eAkte. However, $23.8 \%$ of the participants have a neutral opinion, $19 \%$ do not agree, and $4.8 \%$ strongly disagree with the statement.

Usefulness: The majority of the participants have a positive opinion

Also, regarding the acceptance of the new electronic tool, the participants

about the usefulness of the eAkte for their work (33.3\% totally agree, and $33.3 \%$ agree with the statement). $14.3 \%$ of the participants have a neutral opinion about the usefulness of the tool for their work. $4.8 \%$ do not agree and $4.8 \%$ strongly disagree.

$\square$ fully agree $\square$ tend to agree $\square$ neutral $\square$ tend to disagree $\square$ fully disagree

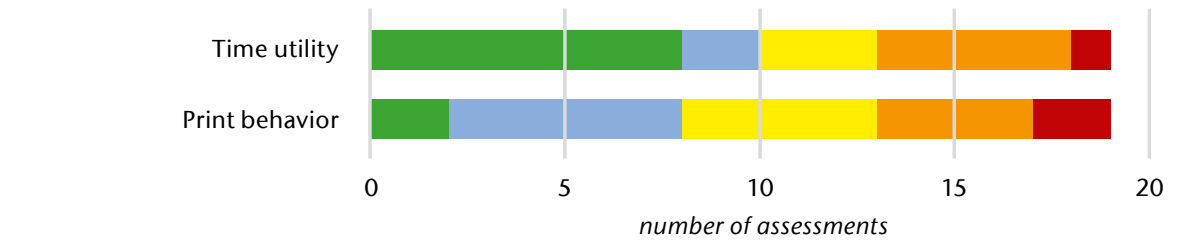

Fig. 1) Usage behaviour

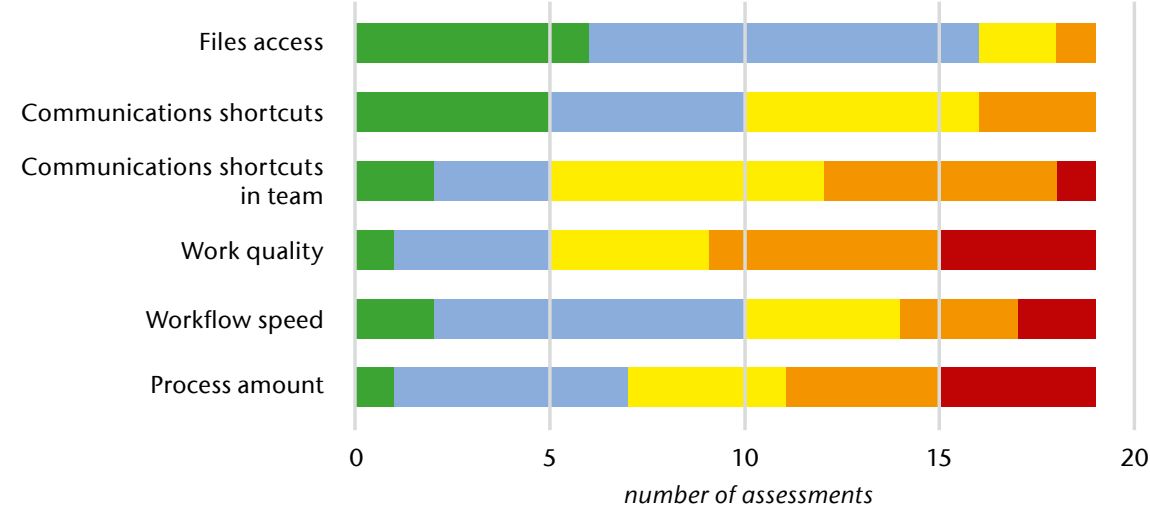

Fig. 2) Perceived advantages of working with the eAkte

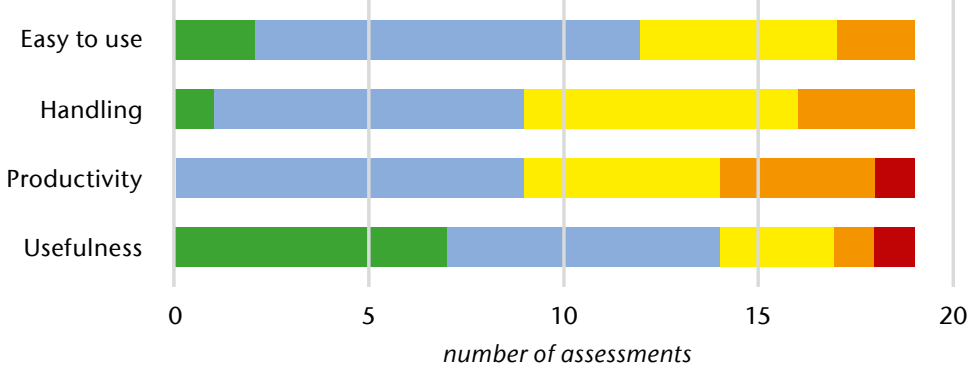

Fig. 3) Technology Acceptance Model (TAM)

Browsability/Searchability

Formatting/Presentation

Mediation

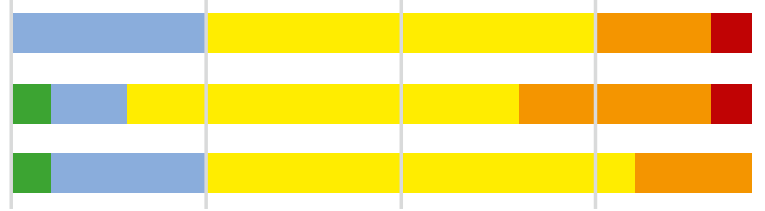

0

10

15 
express their agreement with the tool's usefulness for their work and their productivity. Moreover, they mostly perceive the tool as easy to use, even if in this last case, a third of the participants show a neutral opinion.

\subsection{Attitudes toward the content and functionality of the eAkte}

\subsubsection{User friendliness}

Ease of search facilities (browsability/searchability): A majority of the participants (47.6\%) have a neutral opinion about the ease with which information can be found using the eAkte. $23.8 \%$ of the participants agree that the eAkte is easy to use for information searching. However, $14.3 \%$ of the participants do not agree with the statement, and $4.8 \%$ strongly disagree with it (Fig. 4).

Friendliness of design and format (formatting/presentation): As regards the friendliness of the eAkte's design and format, the majority of the test participants (47.6\%) express a neutral opinion. However, whereas in the positive attitude area, $4.8 \%$ of the participants strongly agree with the statement, and $9.5 \%$ agree with it, in the negative attitude area, $23.8 \%$ of the participants do not agree with the statement, and $4.8 \%$ strongly disagree.

Information guide (mediation): With regard to the statement about the existence of a clear information guide in the system, the majority of the participants $(52.4 \%)$ have a neutral opinion. However, a larger proportion of the participants position themselves as having a positive attitude about the statement: $19 \%$ agree and $4.8 \%$ strongly agree with it, whereas $14.3 \%$ disagree with the statement.

\subsubsection{Information delivery}

Effectiveness of information identification (item identification): In respect to the statement about the effectiveness of identifying information with the eAkte, the majority of the test participants (47.6\%) have a neutral attitude (Fig. 5). Nonetheless, $28.6 \%$ of the participants agree that identifying fully agree tend to agree neutral tend to disagree $\square$ fully disagree

$$
\begin{array}{r}
\text { Item identification } \\
\text { Subject summary } \\
\text { Linkage } \\
\text { Selectivity } \\
\text { Novelty }
\end{array}
$$

0

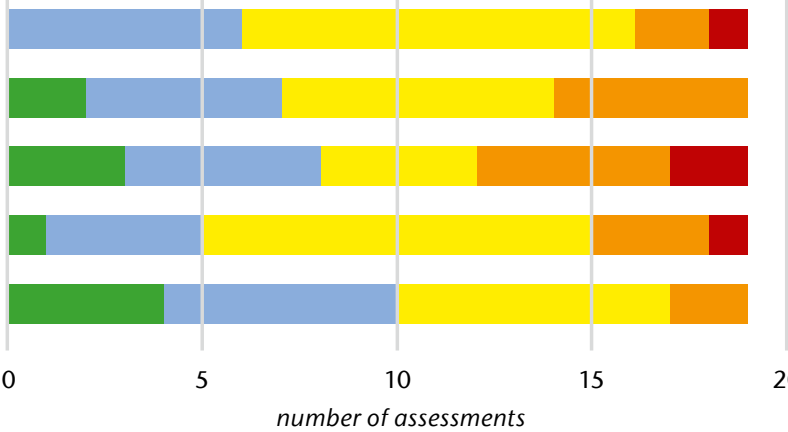

number of assessments
Fig. 5) Information delivery

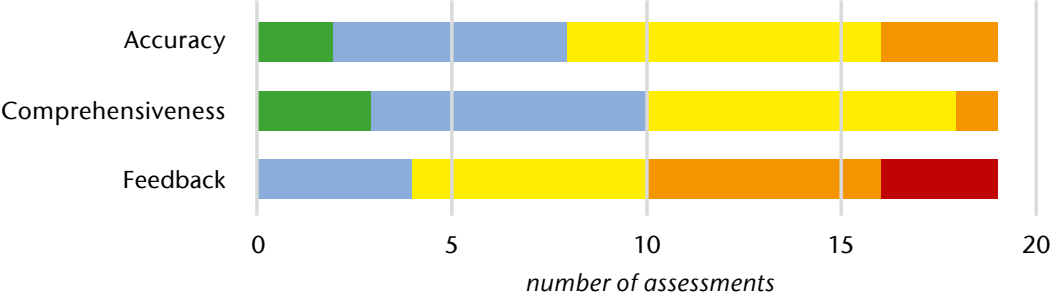

Fig. 6) Quality of the delivered information and feedback

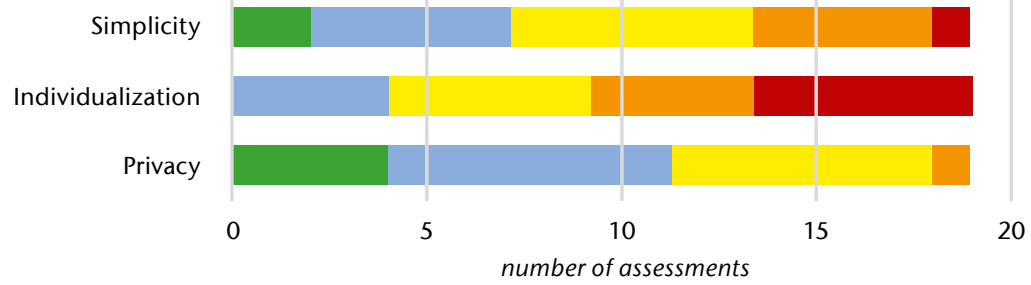

Fig. 7) Adaptability of the eAkte

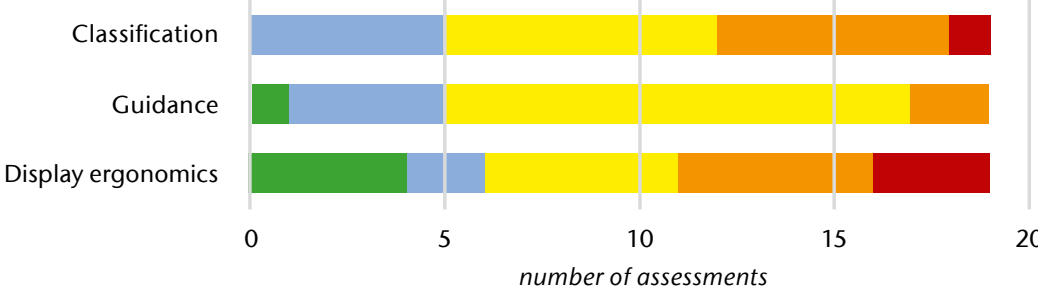

Fig. 8) Additional features

\section{Aesthetics \\ Engagement \\ Satisfaction}

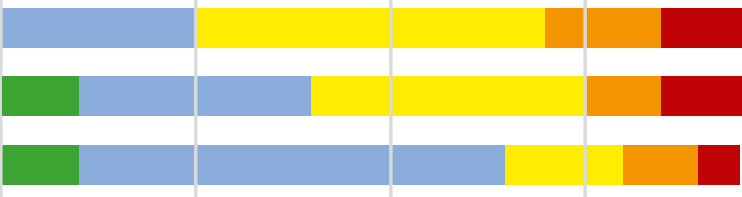

10

15

20

Fig. 9) Emotional Attitudes 
the information using the eAkte is effective for their work. In the negative attitude area, $9.5 \%$ of the participants do not agree, and $4.8 \%$ strongly disagree with the statement.

Information summary (subject summary): As regards the effectiveness of the eAkte's information summary for their work, a majority of the test participants (33.3\%) have a neutral attitude. However, on the positive area of the scale, $23.8 \%$ agree with the effectiveness of the information summary, and $9.5 \%$ strongly agree with the statement. $23.8 \%$ of the test participants do not agree with the statement.

Information linkages (linkage): The attitudes of the test participants toward the effectiveness of the information linkages included in the eAkte are mostly positive: $23.8 \%$ of the participants agree with the statement, and $14.3 \%$ strongly agree with it. $19 \%$ of the participants have a neutral attitude. $23.8 \%$ do not agree with the statement, and $9.5 \%$ strongly disagree.

Information selection (selectivity): The majority of the test participants (42.9\%) agree with the statement that specific information requested can be found using the eAkte. However, 23.8\% have a neutral attitude, $14.3 \%$ do not agree with the statement, and $4.8 \%$ strongly disagree.

Current relevance of the information (novelty): Although a majority of the test participants have a neutral opinion about the current relevance of the information included in the eAkte, most of the participants position themselves on the positive attitude area of the scale: $28.6 \%$ agree with the statement, and $19 \%$ strongly agree with it.

\subsubsection{Quality of the delivered information and feedback}

Accuracy of the information (accuracy): The majority of the test participants (38.1\%) have a neutral opinion about the accuracy of the information included in the eAkte. However, 28.6\% agree that the information included in the tool is accurate, and $9.5 \%$ strongly agree with the statement. $14.3 \%$ do not agree with this statement (Fig. 6).

Completeness of the information (comprehensiveness): Although the majority of the test participants (38.1\%) have a neutral opinion about the completeness of the information available in the eAkte, most of the participants position themselves on the positive area of the attitude scale: $33.3 \%$ of the participants agree with the statement, and $14.3 \%$ strongly agree with it. Only $4.8 \%$ do not agree with the statement.

Feedback: Most of the test participants have a negative attitude about the possibility of giving feedback in the eAkte: $28.6 \%$ do not agree with the statement, and $14.3 \%$ strongly disagree. However, $19 \%$ of the participants agree with the statement, and $28.6 \%$ express a neutral opinion.

\subsubsection{Adaptability of the eAkte}

Design simplicity (simplicity): Although a majority of the test participants $(28.6 \%)$ show a neutral attitude toward the simplicity of the eAkte design (Fig. 7), the proportion of participants positioning themselves on the positive or in the negative area of the attitude scale is relatively even. $23.8 \%$ of the participants agree with the statement, and $9.5 \%$ strongly agree, whereas $23.8 \%$ do not agree, and $4.8 \%$ strongly disagree with the statement.

Individual adaptability (individualization): A majority of the test participants (28.6\%) strongly disagree with the statement that it is possible to customize the tool, while $19 \%$ of the participants disagree with the statement. $23.8 \%$ of the test participants have a neutral attitude toward the statement, and $19 \%$ agree that they have the opportunity to individually adapt the tool.

Data privacy (privacy): As regards the privacy of the data included in the eAkte, most of the test participants have a positive attitude: $33.3 \%$ agree with the statement, and $19 \%$ strongly agree with it. $33.3 \%$ have a neutral opinion, while only $4.8 \%$ of the par- ticipants disagree with the statement. Classification: A majority of the test participants (33.3\%) have a neutral attitude toward the statement that the classification of the information included in the eAkte is helpful for their work (Fig. 8). Nonetheless, most of the participants position themselves in the negative attitude area of the scale: $28.6 \%$ do not agree that the classification is helpful, and $4.8 \%$ strongly disagree with the statement. $23.8 \%$ of the participants agree that the classification of the information is helpful in improving the effectiveness of their work.

User help (guidance): A majority of the test participants (57.1\%) have a neutral attitude toward the statement that the available user help is useful in their work. However, $19 \%$ agree with the statement, and $4.8 \%$ strongly agree with it, while $9.5 \%$ disagree.

Design (display ergonomics): Most of the test participants position themselves in the negative attitude area of the scale: $23.8 \%$ do not agree with the statement that the design of the eAkte is visually helpful for them to complete their work effectively, and $14.3 \%$ strongly disagree with this statement. Nonetheless, $19 \%$ of the participants strongly agree with the statement, and $9.5 \%$ simply agree with it. $23.8 \%$ have a neutral attitude toward the statement.

\subsubsection{Emotional Attitudes}

Aesthetics of the eAkte design: A majority of the test participants (42.9\%) have a neutral attitude toward the statement aesthetics design working with the eAkte. $23.8 \%$ agree with this statement, whereas $14.3 \%$ of the participants do not agree and $9.5 \%$ strongly disagree with it (Fig. 9).

\section{Attractiveness of information and} elements (engagement): $9.5 \%$ of the users strongly agree that the existing system eAkte has a stimulating appeal. About $20 \%$ tend to contradict this. But the majority feels that an attractiveness of the system for their own commitment is quite given or is neutral.

Satisfaction with the eAkte: A major- 
ity of the participants $(52.4 \%)$ are satisfied with the use of the eAkte. $9.5 \%$ strongly agree that they are satisfied with the use of the tool. However, $9.5 \%$ do not agree, and $4.8 \%$ strongly disagree with the statement.

\section{Discussion}

The results of our test show that even if the adoption of the eAkte in the public organization is positive in general terms, some aspects related to the adaptability, the additional features, as well as the possibilities to give feedback about the tool are not very positive among the employees' responses. Particularly the possibility of giving feedback could be an important feature to integrate into the E-Government tool to enable a participatory "innovation journey" of the IT instrument and to enhance the attitudes of the employees toward its use.

Regarding the development of our analysis tool, the integration of the items selected about the attitudes toward the impact of working with an ERS enhances the measuring accuracy of the TEDS instrument, which focuses on the evaluation of Information Artifacts (IA). Until now, this tool has been mostly used for the analysis of web sites. In some cases, it has been used to analyse other types of IA. However, an adaptation and reinterpretation of the included items was needed (Scholl 2015). In the case of the extension of the WISE Work Index, including TAM questions and items, it is related to the perceived advantages of working with the eAkte and allows a specific analysis of the impact of ERS innovations on any work in this regard.

Departing from the concrete descriptive test results described in previous chapters, we can see that the usage behaviour of the document management system eAkte still involves the printing of documents. Even though the duration of using of the eAkte is never shorter than three hours during the working time, the test participants do still print their documents. An open question related to this is, what the possible variations of time use and printing behaviours are and what factors contribute to them. Another important open question concerns the relation between the functionality of the eAkte and the improvement of work quality. As the test results show, a majority of the test participants agree on the impact of the eAkte on the acceleration of delivering work outputs; however, regarding the impact on the improvement of work quality, the results are rather negative. Further analysis should be conducted to find out which specific factors lead to this negative attitude, and whether it is related to TAM items as well. An important additional information to be added to the WISE Work Index is the particular use of the eAkte in the day-to-day work beyond the time use. Depending on the particular function and area of work, the eAkte is more or less relevant for the work of the public organization members. In the next to last section, we include some ideas to improve the accuracy of the WISE Work Index.

\section{Outlook}

In this paper, we have concentrated on the description of the attitudes toward the ERS (particularly the document management system eAkte). However, our new analysis instrument WISE Work Index allows us to further analyse the impact of content and functionality of the ERS on the attitudes toward working with the ERS. Moreover, the WISE Work Index can be applied for longitudinal analysis of innovation with ERS in public organizations. Thus, the WISE Work Index significantly contributes to enhancing the research of innovation in and with E-Government which is still in its infancy.

Other important decisions to be taken for improving the WISE Work Index consists of reducing the number of items and changing the five-point scale. As we can see in our test results, the responses to the last items particularly cumulate in the neutral area (Point 3 of the Likert scale). This could be an indication of the participants' tiredness due to an excessively long questionnaire, a misunderstanding, or the inaccuracy of the item, etc. Already in the beginning of the seventies, it was noted that the decision about the adequate number of points in Likert scales represents a difficult dilemma: the use of a neutral value can easily result in an "escape" for respondents.
Nevertheless, forcing response dichotomies can lead to non-sincere answers: "On the one hand, this is sometimes considered inadvisable because it provides too easy and attractive an escape for respondents who are disinclined to express a definite view. On the other, forcing responses into an agree or disagree format is likely to cause difficulty for many respondents. It is also likely to yield results that are less realistic and more misleading than is true when an intermediate reply is provided for" (Matell \& Jacoby 1972). A decision should also be taken considering a reduction in the number of items. As some participants pointed out, some items corresponding, for example, to the accuracy of information provided are not relevant because the information included in the eAkte cannot be changed or doubted. However, looking beyond the application of the WISE Work Index for analysing other ERS in E-Government, an earlier research about the possibilities of changing the information provided in ERS is needed in order to adapt the items.

For further developing the instrument to extend its application to a wide analysis of innovation in and with E-Government, we aim at conducting a factor analysis as well as a reliability testing of our results. This analysis would go beyond the framework of this paper.

This article is the unabridged version of Ben Ruiz, E., Scholl, M., \& Ehrlich, E. (2016). Exploring the adoption of E-Government Tools with WISE Work Index (shortened version) International conference on Signal Processing, Communication, Power and Embedded System (SCOPES)-2016. 


\section{REFERENCES}

Argyris C, Schön DA (1978) Organizational Learning. A Theory of Action Perspective. Organization development series. Addison-Wesley Pub. Co, Reading, Mass. ISBN: 978-0201001747

Brown JS, Duguid P (1991) Organizational Learning and Communities-of-Practice: Toward a Unified View of Working, Learning, and Innovation. Organizational Science 2(1):40-57

Cicourel AV (1990) The integration of distributed knowledge in collaborative medical diagnosis. In: Galegher J, Kraut RE (eds) Intellectual teamwork. Social and technological foundations of cooperative work. Erlbaum, Hillsdale, NJ, ISBN: 0-8058-0534-6, pp 221-242

Davis FD (1985) A technology acceptance model for empirically testing new end-user information systems: theory and results. Dissertation, Cambridge University

Davis FD, Bagozzi RP, Warshaw PR (1989) User Acceptance of Computer Technology. A Comparison of Two Theoretical Models. Management Science 35(8):982-1003. doi: $10.1287 / \mathrm{mnsc} .35 .8 .982$

Ebbers WE, van Dijk I (2007) Resistance and support to electronic government, building a model of innovation. Government Information Quarterly 24(3):554-575. doi: 10.1016/j.giq.2006.09.008

Hippel Ev (2001) User toolkits for innovation. Journal of Product Innovation Management 18(4):247-257. doi: 10.1111/1540-5885.1840247

Huws U (2003) The making of a cybertariat. Virtual work in a real world, 1. ed. Monthly Review Press, New York, NY. ISBN: 1583670874

King WR, He J (2006) A meta-analysis of the technology acceptance model. Information \& Management 43(6):740-755. doi: 10.1016/j.im.2006.05.003

Matell MS, Jacoby J (1972) Is there an optimal number of alternatives for Likert-scale items? Effects of testing time and scale properties. Journal of Applied Psychology 56(6):506-509. doi: 10.1037/h0033601

Meier R, Ruiz Ben E, Schuppan T (2013) ICT-enabled public sector organisational transformation: Factors constituting resistance to change. Information Polity 18(4)

Ruiz Ben E (2013) Internationale Professionalität. Transformation der Arbeit und des Wissens in transnationalen Arbeitsfeldern. Springer Fachmedien Wiesbaden, Wiesbaden. ISBN: 9783531931838

Ruiz Ben E, Schuppan T (2014) E-Government Innovations and Work Transformations: Implications of the Introduction of Electronic Tools in Public Government Organizations. IJEGR 10(1):1-17. doi: 10.4018/ ijegr.2014010101

Scholl HJ, Eisenberg MB, Dirks L, Carlson TS (2011) The TEDS framework for assessing information systems from a human actors' perspective: Extending and repurposing Taylor's Value-Added Model. J Am Soc Inf Sci Tec 62(4):789-804. doi: 10.1002/asi. 21500

Scholl M (2015) An Implementation of User-Experience-Based Evaluation to Achieve Transparency in the Usage and Design of Information Artifacts. In: Proc 48th Hawai'i Int Conf System Sciences (HICSS), 5-8 Jan 2015, Kaua'i. IEEE, pp 21-32. doi: 10.1109/HICSS.2015.14

Scholl M, Ehrlich E-P, Wiesner-Steiner A, Edich D (2014) The Project TEDS@wildau.TEDS Framework Integration into the Moodle Platform for User-Specific Quality Assurance of Learning Scenarios. In: Proc 47th Hawai'i Int Conf System Sciences (HICSS), 6-9 Jan 2014, Waikoloa. IEEE, ISBN: 978-1-4799-2504-9, pp 1935-1945

Taylor RS (1982) Value-Added Processes in the Information Life Cycle. J Am Soc Inf Sci 33(5):341-346. doi: 10.1002/asi.4630330517
Venkatesh V, Bala H (2008) Technology Acceptance Model 3 and a Research Agenda on Interventions. Decision Sciences 39(2):273-315. doi: 10.1111/j.15405915.2008.00192.x

Venkatesh V, Davis FD (2000) A Theoretical Extension of the Technology Acceptance Model. Four Longitudinal Field Studies. Management Science 46(2):186-204. doi: 10.1287/mnsc.46.2.186.11926

Venkatesh V, Morris MG, Davis GB, Davis FD (2003) User Acceptance of Information Technology: Toward a Unified View. MIS Quarterly 27(3):425-478

Weick KE (1979) The social psychology of organizing, 2. ed. Topics in social psychology. McGraw-Hill Inc, New York. ISBN: 0075548089

\section{AUTHORS}

PD Dr. Esther Ruiz Ben

Technische Universität Berlin (TU Berlin) Technik- und Innovationssoziologie

Prof. Dr. rer. nat. Margit Scholl

Dipl.-Wirt.-Inf. (FH) Ernst Peter Ehrlich

Technische Hochschule Wildau

Fachgebiet Wirtschafts- und Verwaltungsinformatik

E-Mail for correspondence:

margit.scholl@th-wildau.de

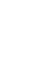

